\title{
Shoulder Dislocation
}

National Cancer Institute

\section{Source}

National Cancer Institute. Shoulder Dislocation. NCI Thesaurus. Code C35020.

A dislocation of the shoulder joint. 